\title{
¿Gritos en la ciudad! Modernización urbana, asesinato en serie y liberación femenina en el cine de terror durante el franquismo (1963-1975)
}

\section{Cries In the City! Urban Modernity, Serial Killing and Female Liberation in the Spanish Horror Film in Franco's Dictatorship (1963-1975)}

\author{
Erika Tiburcio Moreno \\ Universidad Carlos III/Universidad Complutense de Madrid, España \\ etiburci@hum.uczm.es \\ https://orcid.org/0000-0002-5072-3309
}

\begin{abstract}
Resumen:
El artículo se centra en la representación urbana del cine de terror del segundo franquismo como escenario de miedos ante las profundas transformaciones del periodo. La ciudad en el terror español se construyó como espacio degenerado y contenedor de vicios que facilitaba la ruptura con los roles tradicionales.

A través de cuatro películas (Ella y el miedo, El espectro del terror, Una libélula para cada muerto y El sádico de Notre Dame), el asesino en serie urbano encarna una monstruosidad nacida de dos discursos fundamentales. Por un lado, continuó con el relato en otras cinematografías que situaban al monstruo como encarnación de la deshumanización propia de la modernidad. Por otro lado, el fuerte componente conservador de la versión española creó un antagonista que derivaba de la deformación de los valores nacional católicos y patriarcales. Así, el monstruo urbano también simbolizó la inseguridad juvenil ante la persistencia de una represión que endureció sus medidas durante los últimos años de dictadura.
\end{abstract}

\section{Abstract:}

The article focuses on the urban representation in the horror films of the second Franco regime as a scenario of fear in the face of the profound transformations of the period. The city in Spanish horror was constructed as a degenerate space and container of vices that facilitated the rupture with traditional roles.

Through four films (Ella y el miedo, El espectro del terror, Una libélula para cada muerto and El sádico de Notre Dame), the urban serial killer embodies a monstrosity based on two fundamental discourses. On the one hand, Spanish conservatism shaped an antagonist based on distorted National Catholic and patriarchal values. Thus, the urban monster also symbolized youth insecurity before a relentless repression, whose measures were hardened during the last years of the dictatorship.

\section{Palabras clave:}

Cine de terror español; franquismo; asesino en serie; ciudad; modernidad.

Keywords:

Spanish horror film; Franco's dictatorship; Serial killer; City; Modernity. 


\section{Introducción y metodología}

La modernización durante el desarrollismo franquista había impulsado el éxodo rural a las grandes ciudades, el incremento de la renta y la expansión del consumismo. El aperturismo hacia el exterior permitió, además, adoptar modelos y actitudes europeos alejados de los impuestos por el nacionalcatolicismo. A consecuencia de estas profundas transformaciones, los roles femeninos comenzaron a liberarse de sus cadenas y mostrar actitudes más desenfadadas y sensuales, así como una incipiente atención a las necesidades propias. No obstante, la pervivencia del discurso nacional católico acomodó sus ideales patriarcales a representaciones más modernas a través de la publicidad y el cine.

El terror hispano de los últimos años del franquismo, con títulos como $L a$ Residencia (Narciso Ibáñez Serrador, 1969) o La novia ensangrentada (Vicente Aranda, 1972), fue uno de los géneros que exploró en profundidad las tensiones que afloraban en una sociedad cambiante a través de imágenes de violencia gráfica y sexualidad. En ambos títulos, el aislamiento que ofrece el espacio rural se unía a una opresiva atmósfera institucional (La Residencia) y masculina ( $L a$ novia ensangrentada) basada en la coacción física y mental sobre las mujeres.

En el caso urbano, las tensiones asociadas a la modernidad también impregnaron sus historias, en especial aquellas relacionadas con el espacio público, los cambios en la familia o la violencia (Shipka, 2011). Al igual que sucedía con otras cinematografías, además de la asociación entre zombie y ciudad, la serialidad del monstruo humano encarnó las ansiedades en torno a los peligros de las grandes urbes, convirtiéndose en un personaje recurrente del terror de los sesenta y setenta como se puede observar en la estadounidense La última casa a la izquierda (The Last House on the Left, Wes Craven, 1972) o en la italiana El gato de 9 colas (Il gatto a nove code, Dario Argento, 1971).

El objetivo de este artículo es analizar la configuración del imaginario urbano en el cine de terror del franquismo, cuyo discurso se origina en los vínculos establecidos entre ciudad, degeneración y relaciones de género. Los títulos escogidos son Ella y el miedo (León Klimovsky, 1963), El espectro del terror (José María Elorrieta, 1972), Una libélula para cada muerto (León Klimovsky, 1974) y 
El sádico de Notre-Dame (L'éventreur de Notre-Dame, Jesús Franco, 1975)². La elección de dichos títulos responde, primeramente, a su localización urbana, cuyas interconexiones con el horror derivan del alejamiento de los valores nacional católicos. En este sentido, resulta esencial atender a la relación entre la monstruosidad y la ciudad, ya que rompía con la tendencia mayoritaria en el género. Si atendemos a los títulos más populares, entre los que se encontraban La residencia (Narciso Ibáñez Serrador, 1969), El conde Drácula (Jesús Franco, 1969), La noche de Walpurgis (León Klimovsky, 1970) o La noche del terror ciego (Armando de Ossorio, 1971) (Pulido, 2012, pp. 56-57), la localización campestre es la opción mayoritaria donde encontrar el horror. En cambio, en los casos de estudios, la otredad nace de la potencialidad urbana enraizada en el anonimato nocturno.

En segundo lugar, el asesino en serie conectaba con las cinematografías internacionales y permitía adaptar su monstruosidad, inherentemente urbana, a las ansiedades propias de la España de la década de 1960 y 1970. Las transformaciones socioculturales desencadenadas por la apertura del franquismo desde la década de 1950 favorecieron un cambio en las mentalidades colectivas que contradecían la rectitud moral católica. De esta manera, la estricta separación de lo femenino y lo masculino comenzó a difuminarse. La evolución del monstruo coincide así con el propio desarrollo de las nuevas pautas culturales y su amenaza varía desde el ataque a la presencia femenina en la nocturnidad (Ella y el miedo) hasta la persecución y asesinato de aquellas víctimas a las que se consideran corruptas (El espectro del terror y Una libélula para cada muerto).

El último caso, El sádico de Notre-Dame, podría ser inicialmente problemático en este corpus de estudio, por la hibridación de influencias internacionales que revelan las producciones de Jesús Franco debido a que tuvo que realizar una gran parte de sus películas en el extranjero. Sin embargo, en este caso la vinculación al contexto español resulta evidente, ya que su antagonista, un antiguo cura, comete los crímenes atendiendo a la moral católica y a su comprensión del pecado. De

1. Debido a la incongruencia en las fechas de estreno, de resolución y de producción en páginas especializadas de cine como IMDB, en este artículo se considerarán las que aporta la base de datos de películas calificadas del Ministerio de Cultura y Deporte en el Gobierno de España (https://sede.mcu.gob.es/CatalogoICAA/Peliculas/Detalle?Pelicula=606751). 
esta manera, la violencia franquista y la dominación religiosa sirven de base para construir a un personaje sadeano, reconocible para la audiencia española, y que establece un diálogo crítico con las propias raíces de la dictadura (Annandale, 2011). Así, el monstruo de Jesús Franco rememora no solo el pasado traumático de la posguerra española, sino también el fanatismo de las autoridades franquistas al revelarse contra la visión más progresista de determinadas figuras de la jerarquía eclesiástica, como Vicente Enrique y Tarancón.

Desde una perspectiva metodológica, la historia cultural ha sido la disciplina fundamental que ha guiado este estudio. La intrínseca relación entre los acontecimientos traumáticos del siglo XX y el cine de terror moderno (Skal, 2008; Poole, 2018) se reproduce en el caso español mediante narraciones cuya violencia gráfica responde al endurecimiento de la represión sociopolítica y la agresividad durante los últimos años de la dictadura. Asimismo, el análisis fílmico ha servido para relacionar los códigos visuales cinematográficos con las tensiones del tardofranquismo. Finalmente, la perspectiva de género, entendida como un discurso diferenciado entre lo masculino y lo femenino en el establecimiento de las relaciones de poder, ha sido fundamental para comprender tanto la asociación fílmica entre ciudad y dominio masculino como para contextualizar la muestra en el escenario español.

\section{Ciudad y masculinización en el cine de terror}

La imagen negativa de la urbe fue configurada por Horario con el tópico literario del Beatus Ille y continuado por Virgilio en las Geórgicas (29 a.C.). Desde entonces, la idealización de la ruralidad en base a la corrupción urbana ha persistido en la literatura con obras como Lejos del mundanal ruido (Thomas Hardy, 1874), Walden (Henry David Thoreau, 1854) o Hymnica (Luis Antonio Villena, 1975) (Cuvardic García, 2020). En el relato cinematográfico, la ciudad ha estado inherentemente ligada al medio desde su nacimiento (Sorlin, 2001), cuyo imaginario ha variado en función de la visión del cineasta o de la película. Entre 1960 y 1970, la percepción cinematográfica transformó sus calles y plazas en "lugares propicios para derivas, pérdidas y erráticas deambulaciones en las que 
los encuentros casuales, azarosos y frecuentemente traumáticos abren grietas en la experiencia urbana por las que se cuela el pasado negado, reprimido o paralizado como un imaginario de la ciudad colapsada” (Lorente Bilbao, 2015, p. 111).

La cotidianidad de la violencia que impregnaba este escenario fílmico favoreció que el terror convirtiese al núcleo urbano en un espacio asfixiante, inestable e inseguro que exponía la fragilidad de la seguridad humana. En El estrangulador de Boston (The Boston Strangler, Richard Fleischer, 1968), La semilla del diablo (Rosemary's Baby, Roman Polanski, 1968) o Las manos del destripador (Hands the Ripper, Peter Sasdy, 1971) la disidencia y la transgresión de las normas precedían a la muerte (Barber, 2002) y a la experiencia traumática de encontrarse con el horror. Desde una perspectiva histórica, la modernidad y el capitalismo como vías para alcanzar el progreso y la felicidad contrastaban con los enfrentamientos violentos y las agitaciones que asolaban la nación estadounidense (luchas entre la contracultura y el sector conservador, crecimiento de la delincuencia, etc.) o con las confrontaciones sociales en Europa (mayo del 68 francés).

En el caso español, la versión terrorífica de la ciudad se asoció al desorden y el descontrol derivados de la ausencia de supervisión gubernamental. En Jack, el destripador de Londres (José Luis Madrid, 1971), Las amantes del diablo (José María Elorrieta, 1971) o el thriller de terror Aborto criminal (Ignacio Iquino, 1973), el anonimato y las libertades urbanas se expresaban a través de la disidencia inherente al asesinato, los rituales satánicos o la práctica ilegal abortista con fines lucrativos. Desde una perspectiva histórica, dicha incapacidad para ejercer una vigilancia eficaz en los asentamientos urbanos derivados del masivo éxodo rural provocó la desconfianza de las autoridades al considerarlos potenciales vías para la subversión. A diferencia del campo, la masificación en las ciudades facilitó la evasión de tradicionales agentes de vigilancia social (sacerdotes, vecinos) que aseguraban la aplicación de la normativa franquista (Ofer, 2018). Así, la urbe albergó a los principales movimientos de disidencia política (manifestaciones obreras, estudiantiles, grupos terroristas o el asociacionismo vecinal) y facilitó la progresiva ruptura sociocultural con los 
valores del régimen (los jóvenes comenzaron a recibir influencias anglosajonas y europeas que incidían en la relajación de las costumbres) (Gracia García \& Ruiz Carnicer, 2001).

El género de terror exploró dichos desafíos a través de imágenes que vinculaban la nocturnidad a la degeneración urbanas (prostitución, alcoholismo, crímenes). En el caso del asesinato en serie, la figura de Jack el Destripador inició la deformación monstruosa de una modernidad en la que el anonimato favorecía la vulnerabilidad de la víctima y la efectividad del victimario (Warwick, 2006). Posteriormente, la aparición de otros criminales similares (H. H. Holmes, Fritz Haarzman, Ed Gein, etc.) consolidó el discurso en torno a la desviación moral e insistió en la inseguridad ciudadana que acarreaba la despersonalización de los urbanitas.

Dicha deshumanización tuvo su consecuencia más extrema en el Holocausto, cuyo exterminio solo puede comprenderse como el resultado de la incesante burocratización propia de los estados contemporáneos (Bauman, 2019). Así, las terribles consecuencias de la violencia de los fascismos y la Segunda Guerra Mundial desencadenó un trauma cultural emanado del descubrimiento de la maldad humana. La serialidad del asesino en serie tras 1945 perpetuó dicha imagen a través de unos crímenes que recordaban el exceso de la crueldad nacida de la extrema modernidad del Holocausto (Dyer, 2015). En consecuencia, la repetida cosificación de las víctimas, patente en las muestras de violencia física ejercidas sobre sus cuerpos cadavéricos rememoraban el recuerdo de un acontecimiento "dolorosamente difícil tanto de tratar como de olvidar. Tan poderoso es el acontecimiento del nazismo y el Holocausto, y la energía envuelta en tratar con su memoria (represión, limitación, limpieza), que es difícil que no impregne cualquier representación de asesinato repetido y despiadado” (p. 172)². La similitud de la experiencia española facilitaba el vínculo entre el asesinato en serie y la violencia franquista, cuya victoria tras la guerra civil había significado

2. Traducción propia. Texto original: "Painfully hard either to speak about or to forget. So powerful is the fact of Nazism and the Holocaust, and the energy involved in dealing with (repressing, skirting, cleaning) the memory of it, that it is hard for it not also to haunt any representation of remorseless repeat killing". 
la imposición de un estado penal a través del miedo y la regulación del castigo (Pérez-Olivares, 2020). De hecho, la modernización durante el segundo periodo no significó la desaparición de prácticas represivas, sino su modulación a través de la creación de nuevas instituciones como el Tribunal de Orden Público3. Además de ellos, existieron otras herramientas disciplinarias como la brigada político-social, la modernización legislativa a los nuevos desafíos como demuestra la ley 16/1970, de 4 de agosto, sobre peligrosidad y rehabilitación social (1970) o las diferentes prohibiciones de reunión en la vía pública (GarcíaDomenech \& Martí Ciriquian, 2013). De esta manera, la apropiación del nuevo espacio público por parte de las autoridades, así como la reincidencia de las torturas a sospechosos y presos políticos convirtió al asesino en serie en un recordatorio de la persistencia del autoritarismo franquista.

La fragilidad del ciudadano en el terror fílmico oponía la imagen de superación del primer franquismo y, al igual que el terror gótico, desenterraba "lo reprimido a través de imágenes de violencia, gore y desnudos, y en temas como la prostitución, la necrofilia, los actos anti-Católicos ocultos o sacrílegos" (Aldana Reyes, 2017, p. 200)4. En este sentido, la transgresión femenina en la esfera pública funcionó como detonante para la explosión de violencia en estas narrativas, debido a su consideración de ataque a las jerarquías de género (Guerra, 2014) en el territorio urbano, considerado reflejo geográfico del poder estatal (Grosz, 1995). La mirada eminentemente masculina del cine de terror expresó dichas ansiedades a través de un discurso maniqueo en torno a la pureza femenina (García Fernández \& Cordero Domínguez, 2017; Deltell Escolar \& Muñoz Giner, 2020) que impregnaba la totalidad de las narraciones. Como afirma Aintzane Rincón (2014), mientras que la sexualidad masculina no contradecía la idea de matrimonio, la problematización del erotismo femenino exponía la versión actualizada del discurso patriarcal de sumisión y abnegación.

En el terror, el asesinato era la expresión más extrema del castigo a dicha desobediencia (Clover, 2015) y, en el caso español, el exceso superó sus límites a

3. Esta institución, creada en 1963, sustituyó a los tribunales militares para juzgar los delitos de tipo político.

4. Texto original: "The repressed through images of violence, gore and nudity, and in topics like prostitution, necrophilia, the occult or saligious anti-Catholic acts". 
través de un ritual perverso en el que "se aprovechan sexualmente de ellas con deleite o se entregan a pérfidos juegos sádicos. Proliferan primeros planos de cuerpos desnudos embadurnados de sangre, destripados y torturados; momentos en los que se mezclan por igual belleza y repulsión” (Pulido, 2012, p. 50). De esta manera, la masculinidad monstruosa asentó su superioridad sobre la violencia corporal y la defensa del sistema tradicional a través de un discurso cercano al catolicismo más recalcitrante (Lázaro-Reboll, 2012) que agonizaba en la modernidad urbana.

En conclusión, el cine de terror español encontró en los nuevos miedos urbanos una fuente de inspiración para exhibir las ansiedades masculinas. La intrínseca relación entre poder y monstruosidad evidenció, además, la permeabilidad de las estructuras patriarcales a los nuevos espacios urbanos que estaban desafiando su continuidad mediante la difuminación de los límites separadores.

\section{Análisis de películas}

\subsection{Presentación de la muestra}

Las cuatro películas que van a ser analizadas para la muestra son Ella y el miedo, El espectro del terror, Una libélula para cada muerto y El sádico de Notre Dame, realizadas entre 1963 y 1975. Desde una perspectiva cinematográfica, todas ellas coinciden en presentar el terror a través de un asesino en serie que comete crímenes en el escenario urbano. La pátina conservadora que impregnaba el horror de sus historias se unió a la ansiedad social ante las transformaciones que se convirtieron en "una fuente de miedo y de terror, y por extensión algo con el potencial para destruir la sociedad tal y como la audiencia española la conocía” (Willis, 2012, p. 123)5.

La primera de ellas, Ella y el miedo, fue realizada por León Klimovsky en 1963. Este director se convirtió en uno de los autores más importantes del género con obras como La noche de Walpurgis (1971), La orgía nocturna de los vampiros (1973) o Una libélula para cada muerto, incluida en esta muestra. Se trató de una

5. Texto original: "A source of fear and terror, and by extension something with the potential to destroy society as much of the contemporary Spanish audience knew it”. 
producción nacional de CITA Films. Su historia se centra en Laura (May Heatherly), una bailarina de cabaret que deja su trabajo para casarse con Esteban (Virgilio Texeira). En su vuelta a casa por la noche, Laura es testigo de un cruento asesinato en la calle, lo que desemboca en la persecución incesante del asesino para acabar con su vida.

El suspense y el estilo expresionista se mezclan con la búsqueda del miedo en la audiencia, basado en el pánico de la protagonista por ser asesinada por, en palabras de uno de los detectives, un "tipo sádico muy peligroso”. Además, el cartel promocional presentaba un diseño similar a otras películas exploitation (color rojo, foco en el crimen violento, tipografía en amarillo) que incidían en la emocionalidad y en una serie de motivos asociados al género (Lázaro-Reboll, 2012).

El espectro del terror, por su parte, está dirigida por José María Elorrieta y fue estrenada en 1972. La historia se centra en María (Maria Perschy), una mujer acosada por Charlie (Aramis Rey) que ha sido veterano de la guerra de Vietnam y acusado de haber matado a una mujer. Desde ese momento, asesina a mujeres con las que está a punto de tener sexo. En este caso, la película presenta una serie de características asociadas al género como la violencia gráfica o la obsesión misógina con las mujeres. Además, presenta otra característica recurrente denominada "feísmo", según la cual, la estética grotesca y oscura de las pinturas negras de Francisco de Goya se recupera en este género para añadir perturbación al realismo (Schlegel, 2015; Lázaro-Reboll, 2012; Pulido, 2012).

El siguiente título, Una libélula para cada muerto, fue también dirigido por León Klimovsky. En esta ocasión, el cineasta se centra en la investigación de Paolo Scaporella (Paul Naschy) sobre una serie de asesinatos, cuyos cadáveres siempre aparecen con una libélula ensangrentada. En este caso, la película refleja una gran influencia del giallo en el tratamiento de la violencia y los excesos de la modernidad (Shipka, 2011). Al igual que en el género italiano, el filme se centra en la investigación por descubrir la identidad del antagonista, así como en la descripción detallada de los crímenes de un sádico asesino al que no se le ve la cara y lleva ropa negra, y que utiliza diferentes armas (paraguas, hacha...) para acabar con sus víctimas. 
Finalmente, El sádico de Notre Dame, realizada en $1975,{ }^{6}$ cuenta la historia de Mathis Vogel (Jesús Franco), un antiguo sacerdote católico que comienza a asesinar a un grupo de jóvenes porque cree que están poseídos por el demonio y debe salvarlos. En este filme, el laicismo y la depravación urbana se construirán a través de la reconversión de los lugares sagrados y la apertura a recintos sexuales.

\subsection{La ciudad como espacio de terror}

Madrid (Ella y el miedo y El espectro del terror), Milán (Una libélula para cada muerto) y París (El sádico de Notre Dame) son las tres grandes ciudades que enmarcan las películas de la muestra y coinciden en asociar la peligrosidad urbana a la vida nocturna. En Ella y el miedo, la puerta de El molino (el cabaret donde trabaja Laura) se abre al espectador mediante una panorámica y un zoom, descubriendo un escenario con unas chicas bailando un chachachá. El plano general fijo separa el espectáculo de las mesas desde donde el público disfruta de la actuación. A pesar del equilibrio y la tranquilidad de la escena, la nocturnidad, la insinuación al proxenetismo ejercido por el jefe y la diferenciación entre Laura, siendo la única en contraer matrimonio, y el resto de bailarinas reflejan la conexión entre la lujuria y el club.

En El sádico de Notre Dame, la "cueva” se convierte en el lugar de encuentro entre entre extraños, cuya lujuria se infiltra en las conversaciones y en la cercanía al sexo fácil. De hecho, la banalidad de este acto será el antecedente del asesinato de la trabajadora del local, quien ha accedido a irse con Mathis a su casa tras cruzar unas pocas palabras. En El espectro del terror, la discoteca permite ocultar los contactos indebidos entre hombres y mujeres, cuyo montaje de planos medios exhibe el placer femenino a través de sus bailes psicodélicos. En Una libélula para cada muerto, el prostíbulo El Gufo Nero y el local de burlesque, El club Malibú, ambientado con música pop, son el lugar de trabajo de una prostituta y una bailarina que, al acabar su jornada, acaban siendo asesinadas por el monstruo.

6. En 1979, realizó una nueva reedición homónima donde incluyó escenas de este filme y de Sexorcismes (1975). 
La presencia femenina en el espacio público urbano sirve como desencadenante del horror del homicidio violento. En los asesinatos (Una libélula para cada muerto), el sonido de sus tacones siempre precede a un tema estridente que avisa del terrible crimen y refuerza el dramatismo del asesinato. En el filme de Klimovsky, el clímax se acentúa con la aceleración del montaje y primeros planos del arma y el rostro de la víctima. En el caso de Ella y el miedo, el paseo nocturno de Laura desde su trabajo a su casa por unas calles solitarias, sin ningún tipo de sonido salvo una voz masculina que la increpa desde un coche, conduce al asesinato de una joven por parte de un hombre al que no puede ver. La ruptura del silencio con un ritmo musical intensifica la angustia de la persecución por calles desiertas e iluminadas tenuemente. La indefensión ante el encuentro con extraños es explotada en el terror a través de la fragilidad de las víctimas, cuya inseguridad nace de los peligros asociados a la nocturnidad como el crimen o las drogas (Rundell, 2014).

En el caso español, además, la transgresión del orden fue otra de las preocupaciones que impregnaron el imaginario fílmico de la ciudad. Desde una perspectiva histórica, la rápida urbanización vino acompañada del fenómeno del chabolismo y asentamientos desorganizados, donde la ausencia de vigilancia y aparición de nuevos espacios de socialización permitieron el nacimiento del asociacionismo clandestino y una relajación de los comportamientos (Ofer, 2017). Además, el consumismo y la proliferación de locales para jóvenes modificaron las maneras de relacionarse entre ellos, alejándose de las de sus padres. No obstante, la persistencia del discurso tradicional, especialmente en el caso femenino, resultó en una auténtica contradicción. "La nueva versión erotizada de las mujeres (es decir, la de la mujer como mercancía) que aparecía en los medios de comunicación constituía una transgresión de la pureza cristiana y de las relaciones de género que prescribía el franquismo" (Morcillo Gómez, 2015, p. 329). Así, el desorden, la transgresión y la ausencia de vigilancia impregnaron las narrativas urbanas para construir ciudades que necesitaban de la vigilancia constante.

En todas ellas, la policía es un agente esencial en la resolución del caso y en su capacidad para limitar la peligrosidad de la ciudad. La ausencia de vigilancia 
construye la degeneración urbana como espacio carente de valores y propiciatorio de vicios a través de un desfile de personajes (exhibicionista, traficante de drogas o travesti en Una libélula para cada muerto), diálogos eróticos y actos sexuales (orgías en un castillo, conversaciones en una cafetería sobre la búsqueda de vírgenes El sádico de Notre Dame) o la cotidianidad de la prostitución (en Ella y el miedo y en Una libélula para cada muerto, el consumo de sexo por dinero rodea a los protagonistas). En El espectro del terror la amenaza del monstruo impregna la totalidad del espacio y el tiempo, de manera que Charlie es capaz de actuar durante el día y disuadir al policía que lo investiga. Dicha incertidumbre se introduce desde las primeras escenas a través de diferentes técnicas. En una de ellas, tras advertir el acoso de Charlie mientras mira escaparates, María comienza a huir. El tema musical de percusión imprime el ritmo a una persecución relatada a través de la sucesión de planos medios y primeros planos de sus rostros y sus piernas. La calle se convierte así en una estrecha y angustiosa arteria que expone a la víctima ante su verdugo y, a pesar de la presencia de viandantes, el anonimato impide cualquier tipo de ayuda.

La siguiente escena sigue la fórmula comentada previamente, es decir, sonido de pasos envuelto en silencio, alternancia de planos generales, medios y música de piano discordante que avisa de la presencia de Charlie. María sale del avión donde trabaja como azafata y va hacia el parking del aeropuerto. Mediante un plano general del pasillo del aparcamiento, el sonido de los pasos de María alejándose guían al espectador hasta su coche. Los medios y primeros planos de María intentando ponerlo en marcha y verificando el motor son ambientados por un dramático tema de cuerdas que eleva el volumen cuando María repara en que Charlie está observándola desde su asiento trasero. En ese momento, las notas de piano discordantes chirrían y solo dejan escuchar los gritos de la protagonista. Tras un plano-contraplano de ambos, la cámara vuelve al plano inicial para mostrar a María corriendo hacia la cámara. El asalto emocional que impide ignorar el sonido y el plano de Charlie desde el interior del coche (Sipos, 2010) expone la debilidad de las fronteras entre el coche como posesión (y espacio de seguridad) y el parking como territorio de vulnerabilidad. 
La difuminación de límites entre la propiedad y el exterior reincide en la idea de desorden y expone la fragilidad del ciudadano ante la posibilidad de que un extraño irrumpa en su hogar. En Ella y el miedo, la compañera de Laura es asesinada cuando está sola; en El espectro del terror, Charlie observa a María dormir; en Una libélula para cada muerto, el asesino se infiltra en los hogares de las víctimas antes de cometer su crimen; y en El sádico de Notre Dame, Mathis es capaz de entrar en casa de Anna (Lina Romay), secuestrarla y cargarla por el pasillo hasta el alojamiento donde se encuentra sin que nadie se percate.

La constante referencia a la intrusión del monstruo en el hogar ajeno donde desplegar su violencia elimina cualquier tipo de protección ante el exterior. Así, el espacio conocido se vuelve siniestro (Marcucci, 2020) y abierto a la penetración desautorizada del extraño monstruoso que puede encarnar la degeneración urbana. Esta idea aparece a través de las huellas que deja a su paso (el cadáver de la compañera de Laura en el baño en Ella y el miedo), el punto de vista subjetivo del asesino escondido en la casa (en El espectro del terror, mediante un ligero contrapicado y notas de piano inquietantes, la cámara sitúa al espectador desde la perspectiva de Charlie, quien, mientras duerme María, la desnuda con la mirada y consigue tocarla), o con el rostro aterrorizado de la víctima antes de ser asesinada (el plano-contraplano de la víctima masculina y el arma precede al asesinato de la primera víctima en Una libélula para cada muerto).

Así, la ciudad en el género de terror español se convirtió, por un lado, en un escenario de problematización de la modernidad y, por otro, conectó con tendencias internacionales como el giallo italiano o el incipiente slasher. Las drogas, la violencia, la inseguridad y, fundamentalmente, la presencia femenina en la esfera pública, sirvieron como desencadenante del horror ante la incertidumbre y exigían la vigilancia de las autoridades. En todas ellas, el asesino en serie desplegará su poder a través de su capacidad para controlar el territorio y deshumanizar a los que habitan en él.

\subsection{Ciudad como territorio del monstruo}

El asesino en serie no fue un monstruo propiamente español, sino que su éxito traspasó las fronteras norteamericanas y permitió adaptarlo a las distintas 
cinematografías del euro horror. Desde una perspectiva cinematográfica, la búsqueda de dominio y poder sobre sus víctimas a través de la violencia era un elemento que compartía con muchos otros monstruos del terror español (los templarios ciegos, Alaric de Marnac, Waldemar Daninsky). Desde una perspectiva histórica, la configuración de la peligrosidad urbana en las narrativas del asesino en serie permitía también conectar con la conflictividad social de los últimos años del franquismo. Por un lado, el endurecimiento de la represión durante la dictadura conllevó la declaración de varios estados de excepción (1969, 1971) y la continuidad de las penas capitales (Ysàs Solanes, 2004) así como al asesinato de algunos activistas (José María Fuentes Fernández en Galicia) o actuaciones ilícitas (José Luis Cancho fue lanzado desde una ventana en Valladolid) por parte de las autoridades (Ortiz Heras, 2013).

En el cine de terror, la radicalidad política de los jóvenes urbanos desde mediados de los sesenta se representó a través del hedonismo y la falta de disciplina (Willis, 2012), cuyos espacios propios se construían sobre la base del ocultamiento de conductas perniciosas. En El espectro del terror, el bar y la discoteca les permite desinhibirse y hablar sin tapujos gracias a la ausencia de una vigilancia externa. La desmesura y la indiferencia por el crimen se resalta en un bar al que acude Charlie, donde se encuentra a un antiguo compañero de la guerra de Vietnam acompañado de dos chicas. Los tres, completamente ebrios, comienzan a burlarse de Charlie por haber asesinado a una chica en el pasado y ser incapaz de relacionarse adecuadamente con el sexo femenino. La banalización del crimen conlleva a que una de las chicas intente besar a Charlie a pesar de conocer su terrible pasado.

En Una libélula para cada muerto, los hogares de los jóvenes son espacios para el consumo de drogas y sirven de precedente a su asesinato. La primera víctima es asesinada tras pincharse heroína que ha conseguido en la calle y las terceras han estado drogándose y practicando una orgía antes de la irrupción del monstruo. En El sádico de Notre Dame, el retrato urbano de París girará en torno a la liberación sexual y al hedonismo juvenil a través de los diferentes espacios que componen la ciudad: la editorial Venus, del bar juvenil "la cueva" (una antigua iglesia) y del apartamento de Anna y Rose (Nadine Pascal). 
"La cueva" ejemplifica perfectamente la apropiación juvenil del espacio y la ciudad como espacio de libertinaje. Por una parte, un tilt down con música de jazz presenta el lugar a través del baile desinhibido de una trabajadora con minifalda y, a continuación, la cámara se centra en la conversación entre Anna, Rose, el editor y otra chica a la que convencen para participar en una orgía. De hecho, expresiones como "misa negra" se enlazan con la localización de la performance, en una antigua iglesia, siendo la herramienta que utiliza Jesús Franco para escandalizar a través de la profanación juvenil de lo sagrado. Dicho sacrilegio aparece también reflejado en otro diálogo entre Mathis y la trabajadora que bailaba, a la que acabará asesinando por considerarla poseída por el piano. Mediante un plano medio fijo de ella apoyada en él, comentan:

-Trabajadora (T): ¿Me invitas a una copa?

-Mathis (M): Si quieres... Toma lo que quieras

-T: Marina, otro scotch para mí ¿Que estás haciendo aquí tan tarde?

$-\mathrm{M}$ : No soporto los sitios abarrotados.

-T: Es tan triste estar solo.

$-\mathrm{M}$ : Todo es triste. Este lugar... ¿fue una iglesia antes?

-T: ¿A quién le importa qué fuese?

-M: Sí, qué importa.

-T: Por las iglesias7.

De esta manera, la acción purgatoria de Mathis Vogel a través de la violencia conectaba con la reprobación oficial de los comportamientos juveniles y su incitación a castigarlo. Luis Carrero Blanco, mano derecha de Francisco Franco, expresaba dichas ideas en unas declaraciones para el diario $A B C$ :

\section{DEFENSA DE LA JUVENTUD}

La defensa de nuestra juventud de los embates que hoy se lanzan contra ella para corromperla moral y materialmente constituye nuestra más grave responsabilidad. El «dejar hacer», el encogerse de hombros ante esta situación, aceptando cómodamente las consecuencias de esta ofensiva que la juventud padece como «moda de los tiempos», puede que no sea una figura de delito en los códigos humanos, pero sí lo es ante la conciencia de cualquier hombre

7. Diálogo original: Worker (W): Buy me a drink? /Mathis (M): If you like. Take what you want./W: Marina, another scotch. What are you doing here so late?/M: I can't stand crowded places./W: It's sad to be alone./M: Everything's sad. This place... was a church once?/W: Who cares what it was./M: Yes, who cares./W: Here, to churches. 
honrado y desde luego, ante el juicio de Dios. (El pensamiento político de Carrerro Blanco, 1973, p. 40)

La degradación juvenil urbana, intrínsecamente ligada a la liberación femenina y a su presencia en espacios tradicionalmente masculinos (noche, calle), es explorada a través del miedo y rol punitivo del monstruo sobre la disidencia femenina que traspasa los límites permitidos. La mirada del asesino en serie se convierte en una herramienta de control sobre sus presas, las cuales desconocen que han sido cosificadas para después convertirse en meros objetos de placer. Mediante la perspectiva subjetiva, la cámara adopta la posición del monstruo que convierte el espacio urbano en un territorio hostil para la víctima destinado a ser escenario de sus más oscuros instintos (MacDonald, 2013).

En El espectro del terror (José María Elorrieta, 1972), el examen visual de Charlie sobre sus potenciales víctimas en una discoteca, mediante primeros planos y música perturbadora, o la persecución a plena luz del día en una calle con tiendas transformada en un emplazamiento angustioso a través del movimiento nervioso de cámara y la música de suspense, inciden en su dominación espacial. En $E l$ sádico de Notre Dame, se consigue a través de la ruptura de los límites de la intimidad, bien de manera física (infiltrándose en sus propiedades) o a través de su mirada (supervisa desde su ventana a lo que sucede en la propiedad de Anna y su compañera).

Finalmente, dicha vigilancia siempre precede a la victimización y sometimiento femenino a través de la coerción. Por una parte, la inmovilización física se ejerce sobre las mujeres a través del ahogamiento (El espectro del terror) o del forzamiento a mantenerse arrodillada (El sádico de Notre Dame). Por otra parte, el miedo de las mujeres a ser atacadas (El espectro del terror y Ella y el miedo) las mantiene en alerta, naturalizándolas como víctimas dependientes de la supervisión de las autoridades masculinas. En todos los filmes, las autoridades policiales están encarnadas por hombres que cumplen el rol de vigilar y, en mayor o menor grado, son la pieza clave para encontrar al asesino en serie. Así, como expresa Jenny Reburn (2016), la responsabilidad masculina sobre el espacio 
urbano lo convierte en una "realidad represiva e intrusiva hacia las mujeres que deben ser protegidas" (p. 123) ${ }^{8}$.

En conclusión, las narrativas del asesino en serie en el franquismo conectaron la dominación masculina de la ciudad con el conservadurismo del asesino en serie. La ocupación juvenil de la esfera pública, con sus transgresoras relaciones de género, se convierte en objeto de castigo por la mirada conservadora del asesino en serie. Así, la configuración de la ciudad como dominio del asesino en serie insiste en la peligrosidad del espacio urbano, reforzando al mismo tiempo el discurso patriarcal del confinamiento femenino al área doméstica y de la necesaria supervisión masculina como mecanismo de protección y legitimación de su superioridad.

\section{Conclusiones}

El imaginario fílmico de la ciudad y la modernidad tardofranquistas tuvieron una gran importancia en el terror español de los últimos años de la dictadura. Aunque la mayoría de las producciones localizaron el horror en el ámbito rural, existieron un conjunto de películas de terror que abordaron la modernidad en el mismo terreno donde se desarrollaron sus rasgos. El realismo de estas narraciones vino impulsado no solo por el naturalismo estético, sino también por la conceptualización de un monstruo que, a diferencia de zombis, vampiros u hombres lobo, se concibió como un ser humano cuya alteridad residía en su capacidad para cometer una serie de crueles crímenes que nacían del sadismo y de la depravación internas.

La urbanización en España, además, había sido un proceso relativamente rápido y desorganizado que no había contado con la vigilancia de las autoridades. Además, la mejora de la calidad de vida y el acercamiento al estilo de vida extranjero favoreció la rebelión de los jóvenes ante unos valores políticos, sociales y culturales con los que no se identificaban. Asimismo, el ocio nocturno y la aparición de locales destinados a su disfrute alejados de la supervisión adulta

8. Texto original: "reality repressive and intrusive towards the women they are supposed to protect". 
favorecieron la liberación sexual, el acercamiento a las drogas y el acceso femenino al placer y el disfrute propios. Sin embargo, las autoridades franquistas ejercieron una condena persistente del estilo de vida juvenil al considerar sus prácticas moralmente inadecuadas.

El asesino en serie encarnó estas contradicciones a través de la mirada conservadora y masculina de unos cineastas que, aprovechando las tendencias de explotación internacionales, desplegaron toda una serie de agresiones a través de la violencia gráfica y el nudismo. Las melodías pop, el jazz y la música de suspense, así como el montaje rápido y asfixiante de las persecuciones y asesinatos, rodearon a la construcción cinematográfica de la ciudad tardofranquista, cuya hostilidad se enraíza en las estructuras de la dictadura y en la aversión a la ocupación femenina en la esfera pública. El asesino en serie se convirtió en una extensión de la ciudad corrupta, que ejercía una furibunda violencia sobre sus habitantes y castigaba a las mujeres que atentaban contra los valores de la dictadura a través de sus comportamientos impuros.

\section{Referencias bibliográficas}

Aldana Reyes, X. (2017). Spanish Gothic. National Identity, Collaboration and Cultural Adaptation. Londres: Palgrave Macmillan.

Annandale, D. (2011). Dark Imperative: Kant, Sade and Catholicism in Jess Franco's Exorcism. En R. Hansen (ed.), Roman Catholicism in Fantastic Film. Essays on Belief, Spectacle, Ritual and Imagery, Jefferson y Londres: McFarland \& Company.

Barber, S. (2002). Projected Cities. Cinema and Urban Space. Londres: Reaktion Books.

Bauman, Z. (2019). Holocausto y Modernidad ( $9^{\text {a }}$ ed.). Madrid: Sequitur.

Clover, C. (2015). Men, Women, and Chain Saws: Gender in the Modern Horror Film: Gender in the Modern Horror Film. Princeton: Princeton University Press.

Cuvardic García, D. (2020). Vigencia del Beatus ille en la poesía española del siglo XX: reescrituras del tópico en Jaime Gil de Biedma, Luis Antonio de Villena y Erika Martínez. Revista De Fïlología Y Lingüística De La Universidad De Costa Rica, 46(Ext.), 49-65. Recuperado de https://revistas.ucr.ac.cr/index.php/filyling/article/view/43578 DOI: 10.15517/rfl.v46iExt..43578 
Deltell Escolar, L. \& Muñoz Giner, A. (2020). Vera, un cuento cruel (1973) Josefina Molina. El cine de terror visto por una directora. Fotocinema. Revista científica de cine y fotografía, 21, 403-424. Recuperado de https://revistas.uma.es/index.php/fotocinema/article/view/10018/9983 DOI: 10.24310/Fotocinema.2020.vi21.10018

Dyer, R. (2015). Lethal Repetition. Serial Killing in European Cinema. Londres: British Film Institute.

García Fernández, E. C. \& Cordero Domínguez, A. (2017). Sangre y sexo en el cine de terror español. Fotocinema. Revista científica de cine $y$ fotografia, $\quad 15, \quad 37-62 . \quad$ Recuperado de https://revistas.uma.es/index.php/fotocinema/article/view/3496/3199 DOI: 10.24310/Fotocinema.2017.voi15.3496

García-Doménech, S. \& Martí-Ciriquián, P. (2013). ¿Renace el espacio público urbano? Ángulo Recto. Revista de estudios sobre la ciudad como espacio plural, $\quad 5$ (2), 21-36. Recuperado de http://www.ucm.es/info/angulo/volumen/Volumeno52/articulos02.htm DOI: 10.5209/rev_ANRE.2013.v5.n2.43328

Gracia García, J. \& Ruiz Carnicer, M. (2001). La España de Franco (1939-1975). Cultura y vida cotidiana. Madrid: Síntesis.

Grosz, E. (1995). Space, Time, and Perversion. Londres y Nueva York: Routledge.

Guerra, L. (2014). Ciudad, género e imaginarios urbanos en la narrativa latinoamericana. Santiago de Chile: Cuarto propio.

Lázaro-Reboll, A. (2012). Spanish Horror Film. Edimburgo: Edinburgh University Press.

Lorente Bilbao, J. I. (2015). Ciudad, cine y comunicación: escenarios de regeneración urbana. Revista Internacional de Comunicación y Desarrollo, 4, 107-118. Recuperado de https://revistas.usc.gal/index.php/ricd/article/view/3294 DOI: 10.15304/ricd.1.4.3294

Macdonald, A. (2013). Serial Killing, Surveillance, and the State. En A. Macdonald (Ed.), Murders and Acquisitions. Representations of the Serial killer in Popular Culture (pp. 33-48). Nueva York y Londres: Bloomsbury Academic.

Marcucci, D. (2020). Strangers at the Door: Space and Character in HOme Invasion Movies. En F. Pascuzzi \& S. Waters (Eds.), the Spaces and Places of Horror. Wilmington: Vernon Press.

Morcillo Gómez, A. (2015). En cuerpo y alma. Ser mujer en tiempos de Franco. Madrid: siglo XXI.

Ofer, I. (2017). Claiming the City and Contesting the State. Squatting, Community Formation and Democratization in Spain (1955-1986). Nueva York y Oxfordshire: Routledge.

Ortiz Heras, M. (2013). La violencia política en la dictadura franquista 19391977. La insoportable banalidad del mal. Albacete: Editorial Bomarzo. 
Pérez-Olivares, A. (2020). Criminología. Definir el delito, perseguir la desviación, mantener el orden. La criminología y el estudio del franquismo. En Z. Box \& C. Rina (Eds.), El franquismo en caleidoscopio. Perspectivas y estudios transdisciplinares sobre la dictadura (pp. 11-29). Granada: Comares.

Poole, W. S. (2018). Wasteland: The Great War and the Origins of Modern Horror. Berkeley: Counterpoint.

Pulido, J. (2012). La década de oro del cine de terror español. Madrid: T\&B Editores.

Reburn, J. (2016). Profiling the City: Urban Space and the Serial Killer Film. En E. van der Meulen \& R. Heynen (Eds.), Expanding the Gaze. Gender and the Politics of Surveillance (pp. 101-130). Toronto: University of Toronto Press.

Redacción (21 de diciembre de 1973). El pensamiento político de Carrero Blanco, $A B C$, p. 40. Recuperado de https://www.march.es/es/coleccion/archivolinz-transicion-espanola/ficha/--linz:R-17643

Rincón, A. (2014). Representaciones de género en el cine español (1939-1982): figuras y fisuras. Madrid: Centro de Estudios Políticos y Constitucionales.

Rundell, J. (2014). Imagining cities, others: Strangers, contingency and fear. Thesis Eleven, 121(1), 9-22. Recuperado de https://journals.sagepub.com/doi/10.1177/0725513614528783 DOI: 10.1177/0725513614528783

Schlegel, N. (2015). Sex, Sadism, Spain, and Cinema. The Spanish Horror Film. Londres: Rowman \& Littlefield.

Sipos, T. M. (2010). Horror Film Aesthetics. Creating the Visual Language of Fear. Jefferson y Londres: McFarland.

Shipka, D. (2011). Perverse Titillation: The Exploitation Cinema of Italy, Spain and France, 1960-1980. Jefferson: McFarland.

Skal, D. J. (2008). Monster show: una historia cultural del horror. Madrid: Valdemar.

Sorlin, P. (2001). El cine y la ciudad: una relación inquietante. Secuencias: revista de historia de cine, 13, 21-28. Recuperado de http://hdl.handle.net/10486/3869

Warwick, A. (2006). The Scene of the Crime: Inventing the Serial Killer. Social \& Legal Studies, 15(4), 552-569. Recuperado de https://journals-sagepubcom.biblioteca5.uc3m.es/doi/abs/10.1177/0964663906069547 DOI: 10.1177/0964663906069547

Willis, A. (2012). Paul Naschy, Exorcismo and the Reactionary Horrors of Spanish Popular Cinema in the Early 1970s. En P. Allmer, E. Brick \& D. Huxley (Eds.), European Nightmares. Horror Cinema in Europe since 1945 (pp. 121-130). Londres y Nueva York, NY: Wallflower Press.

Ysàs Solanes, P. (2004). Disidencia y subversión. La lucha del régimen franquista por su supervivencia, 196o-1975. Barcelona: Crítica. 


\section{Filmografía}

Elorrieta, J. M. (1972). El espectro del terror. España: Films Internacionales (FISA)

Franco, J. (1975). L'éventreur de Notre-Dame. Bélgica, Francia, España: Celtelci S.A., Eurociné, Gold International Films.

Klimovsky, L. (1963). Ella y el miedo. España: Cita Films.

Klimovsky, L. (1974). Una libélula para cada muerto. España: Profilmes, CC Astro. 